\title{
The effect of radiotherapy in liver-confined but non-resectable Barcelona Clinic Liver Cancer stage C large hepatocellular carcinoma
}

\author{
Hong In Yoon ${ }^{1,4}$, Inkyung Jung ${ }^{2}$, Kwang-Hyub Han ${ }^{3,4}$ and Jinsil Seong ${ }^{1,4}$ \\ ${ }^{1}$ Department of Radiation Oncology, Yonsei Cancer Center, Yonsei University College of Medicine, Yonsei University Health \\ System, Seoul, Korea \\ ${ }^{2}$ Department of Biostatistics \& Medical Informatics, Yonsei University College of Medicine, Seoul, Korea \\ ${ }^{3}$ Department of Internal Medicine, Yonsei University College of Medicine, Yonsei University Health System, Seoul, Korea \\ ${ }^{4}$ Korean Liver Cancer Study Group, Seoul, Korea \\ Correspondence to: Jinsil Seong, email: jsseong@yuhs.ac \\ Keywords: large hepatocellular carcinoma, radiotherapy, BCLC stage C, median survival time, propensity score matching \\ Received: April 13,2016 Accepted: June 17, $2016 \quad$ Published: July 28, 2016
}

\section{ABSTRACT}

Background and aims: Clinical trials to determine the efficacy of radiotherapy (RT) in liver-confined but non-resectable Barcelona Clinic Liver Cancer (BCLC) stage C hepatocellular carcinoma (HCC) are scarce. We aimed to determine the benefit of RT in such tumors and investigated large HCC tumors.

Methods: HCC data from the Korea Central Cancer Registry recorded from 2008 to $\mathbf{2 0 1 0}$ were used. A total of $\mathbf{5 9 3}$ patients met our inclusion criteria; 67 were treated with $R T$ while the remainder made up the non-RT group. Fifty-two $R T$ recipients underwent combination treatments within 4 weeks after the first RT treatment, and were defined as the combination RT group. We performed propensity score matching (PSM) to compare the RT or combination RT groups with the non-RT group. The endpoint was overall survival (OS).

Results: Median follow-up time for surviving patients was 48 months. After PSM, there was no difference in OS between the RT and non-RT groups or between the combination RT and non-RT groups. However, the combination RT group had a longer median survival time (MST) (10.7 vs. 6.9 months, respectively). Next, we conducted PSM between the combination RT and non-RT groups in patients with tumor sizes $\geq 10 \mathrm{~cm}$; MST was significantly longer in the former group (10.1 vs. 5.4 months, respectively; bootstrap 95\% confidence interval of the difference in MST: 0.2-11.8).

Conclusions: As a combined modality, RT is a plausible therapeutic option for liver-confined but non-resectable BCLC stage C large HCC patients.

\section{INTRODUCTION}

Currently, the Barcelona Clinic Liver Cancer (BCLC) staging system serves as a major treatment guideline [1]. BCLC stage C (advanced stage) hepatocellular carcinoma (HCC) is highly aggressive, and has a dismal survival rate despite the clinical introduction of sorafenib, a multi-tyrosine kinase inhibitor [2, 3]. BCLC stage $\mathrm{C}$ HCC is very heterogeneous, and shows diverse patterns ranging from liver-confined $\mathrm{HCC}$ with portal vein tumor thrombosis to extrahepatic disseminated HCC.
Due to the aggressiveness and heterogeneity of BCLC stage C HCC, sub-classification and optimal therapeutic approaches require further investigation.

The multimodal approach is a basic oncologic principle that has been successful in most types of locally advanced cancers. It often involves performing chemotherapy and radiotherapy, followed by surgery if possible [4-6]. Some researchers have examined whether the inclusion of RT in the multimodal approach enhances the survival outcome for BCLC stage C HCC [7-9], and the optimal criteria for local RT have also been evaluated 
$[10,11]$. However, clinical trials for high-level evidence to establish the benefit of additional local RT for BCLC stage $\mathrm{C} \mathrm{HCC}$ are still lacking.

We recently reported that hepatic arterial infusion concurrent chemoradiotherapy could improve survival for patients with locally advanced HCC with good performance and normal liver function when comparing our institution's database to that of the Korean Liver Cancer Study Group (KLCSG) nationwide multicenter HCC cohort treated between 2003 and 2005 [9]. However, this retrospective study compared two independent databases with different treatment periods. Furthermore, patients who underwent sorafenib treatment were not included because the KLCSG database was constructed before the sorafenib era. Therefore, additional studies are required to confirm our previous finding.

In this study, we investigated the efficacy of RT, as well as combination therapy involving RT, in comparison to other treatments for liver-confined but non-resectable BCLC stage C HCC using a nationwide database constructed from a multi-center HCC cohort that was based on the Korea Central Cancer Registry. We also ascertained the survival benefit of RT in bulky liverconfined but non-resectable BCLC stage C HCC.

\section{RESULTS}

\section{Patient characteristics and survival analysis before PSM}

The characteristics of all the enrolled patients before propensity score matching (PSM) are listed in Table 1. There was a significant difference in performance status (PS), portal vein (PV) invasion, age, tumor size, and $\alpha$-fetoprotein (AFP) levels between the 2 groups. The median ages of patients in the RT and non-RT groups were $51(26-83)$ and $57(8-98)$ years, respectively $(P=0.001)$. The RT group had significantly better PS than the nonRT group; however, the RT group exhibited significantly worse prognostic factors than the non-RT group, including larger tumor size, higher AFP levels, and greater PV invasion. The Child Pugh score was not statistically different between the RT and non-RT groups, although

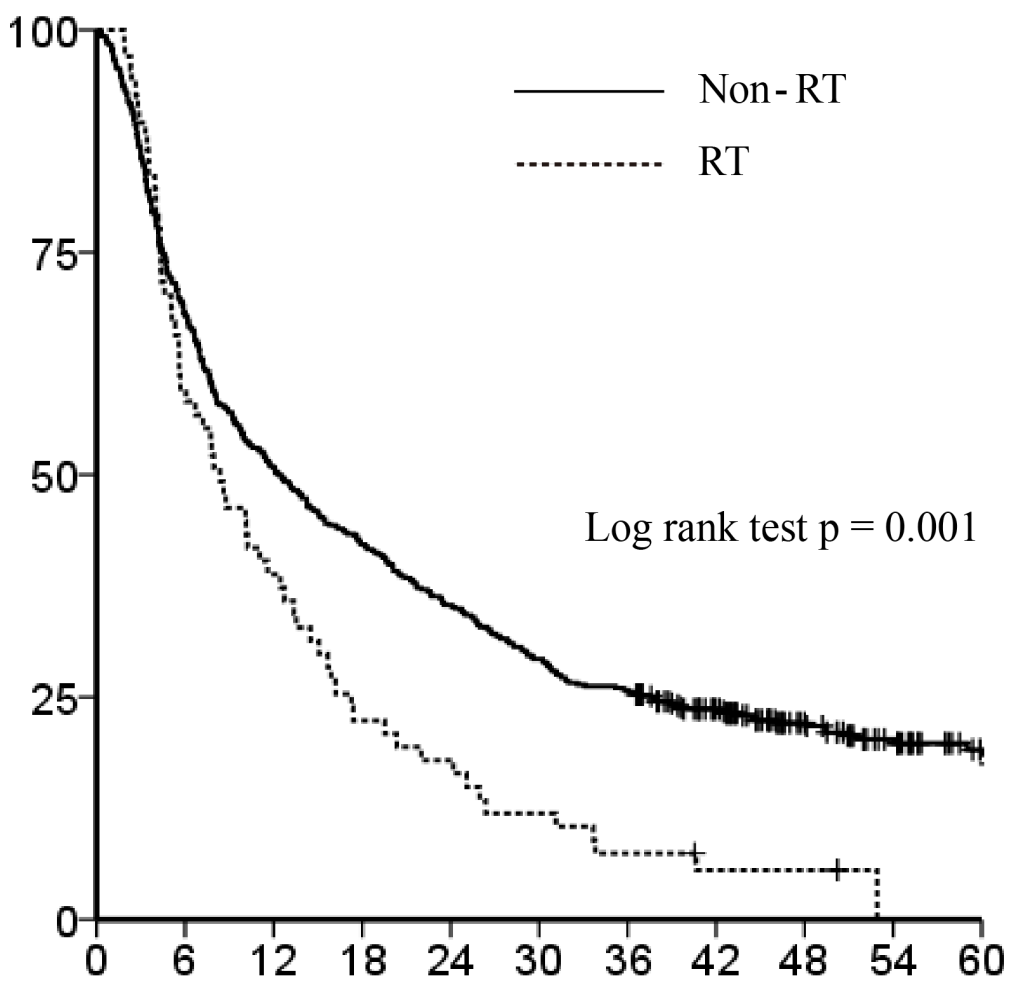

No. at risk

$\begin{array}{rccccccccccc}\text { Non-RT } & 526 & 358 & 268 & 222 & 186 & 154 & 125 & 88 & 58 & 35 & 15 \\ \text { RT } & 67 & 40 & 26 & 15 & 12 & 8 & 5 & 3 & 2 & 0 & 0\end{array}$

Figure 1: Overall survival before propensity score matching. The Kaplan-Meier survival curve shows that the non-radiotherapy (RT) group showed significantly longer overall survival than the RT group (median survival time 12.3 vs. 8.4 months, $P=0.001$ ). 
Table 1: Baseline characteristics for whole cohort

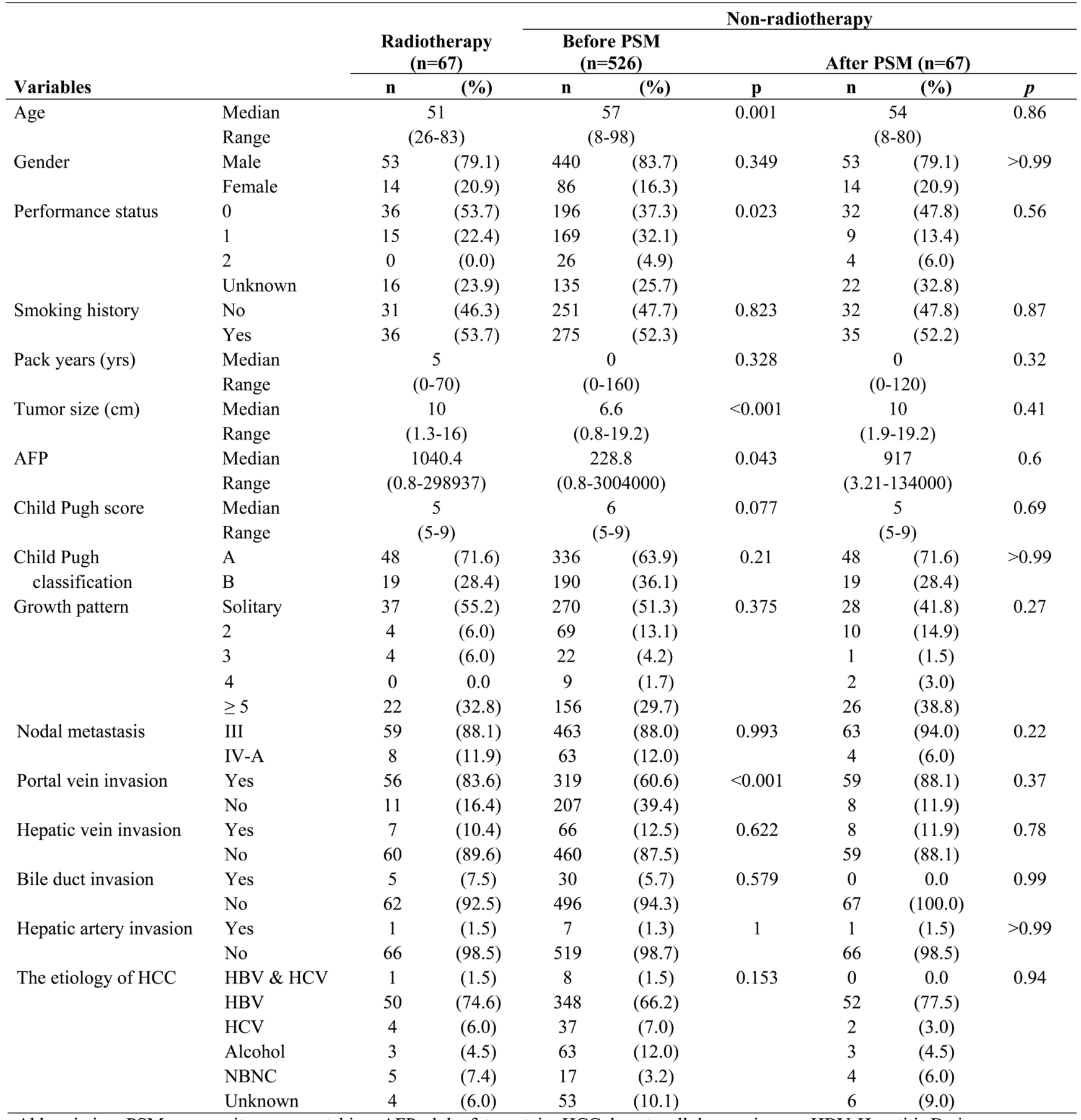

Abbreviation: PSM, propensity score matching; AFP, alpha fetoprotein; HCC, hepatocellular carcinoma; HBV, Hepatitis B virus;

HCV, Hepatitis C virus; NBNC, non-HBV and non-HCV

there was marginal significance $(P=0.077)$.

Median follow-up time for surviving patients was 48 months (range, 36.6-72.5 months). Before PSM, KaplanMeier analyses demonstrated that the non-RT group exhibited significantly longer overall survival (OS) than the RT group (median survival time [MST] 12.3 vs. 8.4 months respectively, $P=0.001$, Figure 1). Because the RT group showed more adverse prognostic factors than the non-RT group, we performed PSM analysis to adjust for the significant differences in baseline characteristics between the 2 groups.

\section{RT versus non-RT group outcomes after PSM}

After PSM between the RT $(n=67)$ and non-RT ( $n$ $=526$ ) groups, all clinical factors were evenly distributed 
Table 2: Baseline characteristics between combination RT and non-RT groups for whole cohort

\begin{tabular}{|c|c|c|c|c|c|c|c|c|c|}
\hline \multirow[b]{3}{*}{ Variables } & & \multirow{2}{*}{\multicolumn{2}{|c|}{$\begin{array}{l}\text { Radiotherapy } \\
(\mathbf{n}=\mathbf{5 2})\end{array}$}} & \multicolumn{6}{|c|}{ Non-radiotherapy } \\
\hline & & & & \multicolumn{2}{|c|}{$\begin{array}{c}\text { Before PSM } \\
(n=526)\end{array}$} & \multicolumn{4}{|c|}{$\begin{array}{c}\text { After PSM } \\
(n=52)\end{array}$} \\
\hline & & n & $(\%)$ & n & $(\%)$ & $p$ & $\mathbf{n}$ & $(\%)$ & $p$ \\
\hline \multirow[t]{2}{*}{ Age } & Median & \multicolumn{2}{|c|}{51} & \multicolumn{2}{|c|}{57} & 0.001 & \multicolumn{2}{|c|}{52} & 0.55 \\
\hline & Range & \multicolumn{2}{|c|}{$(26-83)$} & \multicolumn{2}{|c|}{$(8-98)$} & & \multicolumn{2}{|c|}{$(35-74)$} & \\
\hline \multirow[t]{2}{*}{ Gender } & Male & 43 & $(82.7)$ & 440 & $(83.7)$ & 0.859 & 47 & $(90.4)$ & 0.290 \\
\hline & Female & 9 & $(17.3)$ & 86 & $(16.3)$ & & 5 & $(9.6)$ & \\
\hline \multirow[t]{4}{*}{ Performance status } & 0 & 31 & $(59.6)$ & 196 & $(37.3)$ & 0.011 & 30 & $(57.7)$ & $>0.99$ \\
\hline & 1 & 10 & $(19.2)$ & 169 & $(32.1)$ & & 10 & $(19.2)$ & \\
\hline & 2 & 0 & $(0.0)$ & 26 & $(4.9)$ & & 1 & $(1.9)$ & \\
\hline & Unknown & 11 & $(21.2)$ & 135 & $(25.7)$ & & 11 & $(21.2)$ & \\
\hline \multirow[t]{2}{*}{ Smoking history } & No & 21 & $(40.4)$ & 251 & $(47.7)$ & 0.312 & 22 & $(42.3)$ & 0.86 \\
\hline & Yes & 31 & $(59.6)$ & 275 & $(52.3)$ & & 30 & $(57.7)$ & \\
\hline \multirow[t]{2}{*}{ Pack years (yrs) } & Median & \multirow{2}{*}{\multicolumn{2}{|c|}{$\begin{array}{c}8 \\
(0-70)\end{array}$}} & \multicolumn{2}{|c|}{0} & 0.087 & \multicolumn{2}{|c|}{10} & 0.86 \\
\hline & Range & & & \multicolumn{2}{|c|}{$(0-160)$} & & & & \\
\hline \multirow[t]{2}{*}{ Tumor size $(\mathrm{cm})$} & Median & \multicolumn{2}{|c|}{10} & & & $<0.001$ & & & 0.59 \\
\hline & Range & & & & $.2)$ & & & $9.2)$ & \\
\hline AFP & Median & & & & & 0.153 & & & 0.35 \\
\hline & Range & & 0000) & $(0.8$ & 4000) & & $(1.0$ & 4000) & \\
\hline Child Pugh score & Median & & & & & 0.004 & & & 0.68 \\
\hline & Range & & & & & & & & \\
\hline Child Pugh & A & 42 & (80.8) & 336 & $(63,9)$ & 0.015 & 42 & $(80.8)$ & $>0.99$ \\
\hline classification & B & 10 & (19.2) & 190 & $(36.1)$ & & 10 & (19.2) & \\
\hline Growth pattern & Solitary & 30 & $(57.7)$ & 270 & $(51.3)$ & 0.353 & 30 & (57.6) & 0.77 \\
\hline & 2 & 3 & $(5.8)$ & 69 & (13.1) & & 2 & $(3.9)$ & \\
\hline & 3 & 4 & $(7.7)$ & 22 & $(4.2)$ & & 2 & (3.9) & \\
\hline & 4 & 0 & 0.0 & 9 & $(1.7)$ & & 0 & $(3.0)$ & \\
\hline & $\geq 5$ & 15 & $(28.8)$ & 156 & $(29.7)$ & & 18 & (34.6) & \\
\hline Nodal metastasis & III & 45 & $(86.5)$ & 463 & $(88.0)$ & 0.754 & 51 & $(98.1)$ & 0.07 \\
\hline & IV-A & 7 & (13.5) & 63 & $(12.0)$ & & 1 & $(1.9)$ & \\
\hline Portal vein invasion & Yes & 44 & $(84.6)$ & 319 & $(60.6)$ & 0.001 & 45 & $(86.5)$ & 0.76 \\
\hline & No & 8 & $(15.4)$ & 207 & (39.4) & & 7 & $(13.5)$ & \\
\hline Hepatic vein invasion & Yes & 5 & $(9.6)$ & 66 & (12.5) & 0.539 & 8 & (15.4) & 0.33 \\
\hline & No & 47 & $(90.4)$ & 460 & $(87.5)$ & & 44 & $(84.6)$ & \\
\hline Bile duct invasion & Yes & 3 & $(5.8)$ & 30 & $(5.7)$ & $>0.99$ & 3 & $(5.8)$ & $>0.99$ \\
\hline & No & 49 & $(94.2)$ & 496 & $(94.3)$ & & 49 & $(94.2)$ & \\
\hline Hepatic artery invasion & Yes & 1 & $(1.9)$ & 7 & $(1.3)$ & 1 & 0 & 0.0 & 0.99 \\
\hline & No & 51 & (98.1) & 519 & $(98.7)$ & & 52 & $(100.0)$ & \\
\hline The etiology of $\mathrm{HCC}$ & $\mathrm{HBV} \& \mathrm{HCV}$ & 1 & $(1.9)$ & 8 & $(1.5)$ & 0.175 & 2 & $(3.9)$ & 0.97 \\
\hline & $\mathrm{HBV}$ & 36 & $(69.2)$ & 348 & $(66.2)$ & & 39 & $(75.0)$ & \\
\hline & $\mathrm{HCV}$ & 4 & $(7.7)$ & 37 & $(7.0)$ & & 5 & $(9.6)$ & \\
\hline & Alcohol & 3 & $(5.8)$ & 63 & $(12.0)$ & & 2 & (3.9) & \\
\hline & NBNC & 5 & $(9.6)$ & 17 & $(3.2)$ & & 1 & (1.9) & \\
\hline & Unknown & 3 & $(5.8)$ & 53 & $(10.1)$ & & 3 & $(5.7)$ & \\
\hline
\end{tabular}

Abbreviation: PSM, propensity score matching; AFP, alpha fetoprotein; HCC, hepatocellular carcinoma; HBV, Hepatitis B virus;

$\mathrm{HCV}$, Hepatitis C virus; NBNC, non-HBV and non-HCV

between each group (Table 1). Survival curves indicated that the MST of the RT group was not significantly different from that of the non-RT group (8.4 vs. 8.4 months, hazard ratio [HR] 1.34, 95\% confidence interval (CI) $0.94-1.91, P=0.11$, Figure 2).

\section{Combination RT versus non-RT groups after PSM analysis}

As described above, the RT group included patients who underwent RT alone $(n=15)$ and in combination with other treatments $n=52$ ). We compared the OS in the RT alone, combination RT, and non-RT groups before 
Table 3: Baseline characteristics between combination RT and non-RT groups in subgroup of tumor size $\geq 10 \mathrm{~cm}$

\begin{tabular}{|c|c|c|c|c|c|c|c|c|c|}
\hline \multirow{3}{*}{ Variables } & & \multirow{2}{*}{\multicolumn{2}{|c|}{$\begin{array}{l}\text { Radiotherapy } \\
\quad(n=31)\end{array}$}} & \multicolumn{6}{|c|}{ Non-radiotherapy } \\
\hline & & & & \multicolumn{2}{|c|}{ Before PSM $(n=169)$} & \multicolumn{4}{|c|}{ After PSM $(n=31)$} \\
\hline & & $\mathbf{n}$ & $(\%)$ & $\mathbf{n}$ & $(\%)$ & $p$ & $\mathbf{n}$ & $(\%)$ & $p$ \\
\hline \multirow[t]{2}{*}{ Age } & Median & \multicolumn{2}{|c|}{51} & \multicolumn{2}{|c|}{53} & 0.045 & \multicolumn{2}{|c|}{52} & 0.66 \\
\hline & Range & \multicolumn{2}{|c|}{$(26-83)$} & \multicolumn{2}{|c|}{$(8-85)$} & \multicolumn{4}{|c|}{$(33-80)$} \\
\hline \multirow[t]{2}{*}{ Gender } & Male & 25 & $(80.7)$ & 145 & $(85.8)$ & 0.424 & 24 & (77.4) & $>0.99$ \\
\hline & Female & 6 & $(19.3)$ & 24 & $(14.2)$ & & 7 & $(22.6)$ & \\
\hline \multirow[t]{4}{*}{ Performance status } & 0 & 16 & $(51.6)$ & 76 & $(45.0)$ & 0.575 & 15 & $(48.4)$ & 0.56 \\
\hline & 1 & 6 & $(19.4)$ & 32 & $(18.9)$ & & 5 & $(16.1)$ & \\
\hline & 2 & 0 & $(0.0)$ & 4 & $(2.4)$ & & 1 & $(3.2)$ & \\
\hline & Unknown & 9 & $(29.0)$ & 57 & $(33.7)$ & & 10 & $(32.3)$ & \\
\hline \multirow[t]{2}{*}{ Smoking history } & No & 12 & $(38.7)$ & 67 & $(39.6)$ & 0.922 & 15 & $(48.4)$ & 0.87 \\
\hline & Yes & 19 & $(61.3)$ & 102 & $(60.4)$ & & 16 & $(51.6)$ & \\
\hline \multirow[t]{2}{*}{ Pack years (yrs) } & Median & \multicolumn{2}{|c|}{7} & \multicolumn{2}{|c|}{7} & 0.862 & \multicolumn{2}{|c|}{0} & 0.22 \\
\hline & Range & \multicolumn{2}{|c|}{$(0-70)$} & \multicolumn{2}{|c|}{$(0-80)$} & & \multicolumn{2}{|c|}{$(0-45)$} & \\
\hline Tumor size $(\mathrm{cm})$ & Median & & & & & 0.013 & & & 0.64 \\
\hline & Range & & & & & & & & \\
\hline AFP & Median & & & & & 0.175 & & & 0.43 \\
\hline & Range & & $0000)$ & $(1.7$ & 4000) & & $(2$. & 1000) & \\
\hline Child Pugh score & Median & & & & & 0.176 & & & 0.07 \\
\hline & Range & & & & & & & & \\
\hline Child Pugh & A & 24 & $(77.4)$ & 108 & $(63.9)$ & 0.144 & 17 & $(54.8)$ & $>0.99$ \\
\hline classification & $\mathrm{B}$ & 7 & $(22.6)$ & 61 & $(36.1)$ & & 14 & $(45.2)$ & \\
\hline Growth pattern & Solitary & 17 & $(54.8)$ & 77 & $(45.6)$ & 0.625 & 10 & $(32.3)$ & 0.27 \\
\hline & 2 & 1 & $(3.2)$ & 13 & $(7.7)$ & & 2 & $(6.5)$ & \\
\hline & 3 & 1 & $(3.2)$ & 3 & $(1.8)$ & & 0 & 0.0 & \\
\hline & 4 & 0 & 0.0 & 1 & $(0.6)$ & & 1 & $(3.2)$ & \\
\hline & $\geq 5$ & 12 & $(38.8)$ & 75 & $(44.4)$ & & 18 & $(58.0)$ & \\
\hline Nodal metastasis & III & 29 & $(93.5)$ & 144 & $(85.2)$ & 0.265 & 28 & $(90.3)$ & 0.22 \\
\hline & IV-A & 2 & $(6.5)$ & 25 & $(14.8)$ & & 3 & $(9.7)$ & \\
\hline Portal vein invasion & Yes & 28 & $(90.3)$ & 128 & $(75.7)$ & 0.072 & 29 & $(93.5)$ & 0.37 \\
\hline & No & 3 & $(9.7)$ & 41 & $(24.3)$ & & 2 & $(6.5)$ & \\
\hline Hepatic vein invasion & Yes & 4 & $(12.9)$ & 24 & $(14.2)$ & $>0.99$ & 4 & (12.9) & 0.78 \\
\hline & No & 27 & (87.1) & 145 & $(85.8)$ & & 27 & $(87.1)$ & \\
\hline Bile duct invasion & Yes & 1 & $(3.2)$ & 8 & $(4.7)$ & $>0.99$ & 2 & $(6.5)$ & 0.99 \\
\hline & No & 30 & $(96.8)$ & 161 & $(95.3)$ & & 29 & $(93.5)$ & \\
\hline Hepatic artery invasion & Yes & 1 & $(3.2)$ & 1 & $(0.6)$ & 0 & 0 & 0.0 & $>0.99$ \\
\hline & No & 30 & $(96.8)$ & 168 & $(99.4)$ & & 31 & $(100.0)$ & \\
\hline The etiology of $\mathrm{HCC}$ & $\mathrm{HBV} \& \mathrm{HCV}$ & 0 & 0.0 & 0 & 0.0 & 0.06 & 0 & 0.0 & 0.94 \\
\hline & $\mathrm{HBV}$ & 22 & $(71.0)$ & 122 & $(72.2)$ & & 22 & (71.0) & \\
\hline & $\mathrm{HCV}$ & 2 & $(6.5)$ & 7 & $(4.1)$ & & 4 & (12.9) & \\
\hline & Alcohol & 1 & $(3.2)$ & 20 & (11.8) & & 1 & $(3.2)$ & \\
\hline & NBNC & 4 & (12.9) & 4 & $(2.4)$ & & 3 & $(9.7)$ & \\
\hline & Unknown & 2 & $(6.5)$ & 16 & $(9.5)$ & & 1 & $(3.2)$ & \\
\hline
\end{tabular}

Abbreviation: PSM, propensity score matching; AFP, alpha fetoprotein; HCC, hepatocellular carcinoma; HBV, Hepatitis B virus;

HCV, Hepatitis C virus; NBNC, non-HBV and non-HCV

PSM. Figure 3 shows that the non-RT and combination RT groups had significantly longer MSTs than the RT alone group (12.3 vs. 10.2 vs. 4.6 months, respectively; $P=0.0002$ ). Thus, we performed a second PSM analysis between the combination RT and non-RT groups to verify the effect of RT when combined with other treatments (Table 2). Before PSM analysis, there was a significant difference in PS, PV invasion, age, tumor size, Child Pugh score, and Child Pugh classification between the 2 groups. After PSM analysis using covariates that showed substantial differences between the combination RT and non-RT groups, all clinical factors were distributed evenly. In this case, the survival outcomes of the combination RT and non-RT groups were not significantly different, although the former group had a longer MST (10.7 vs. 6.9 months, respectively; HR 1.01, 95\% CI 0.65-1.55, $P=$ 0.98, Figure 4). 


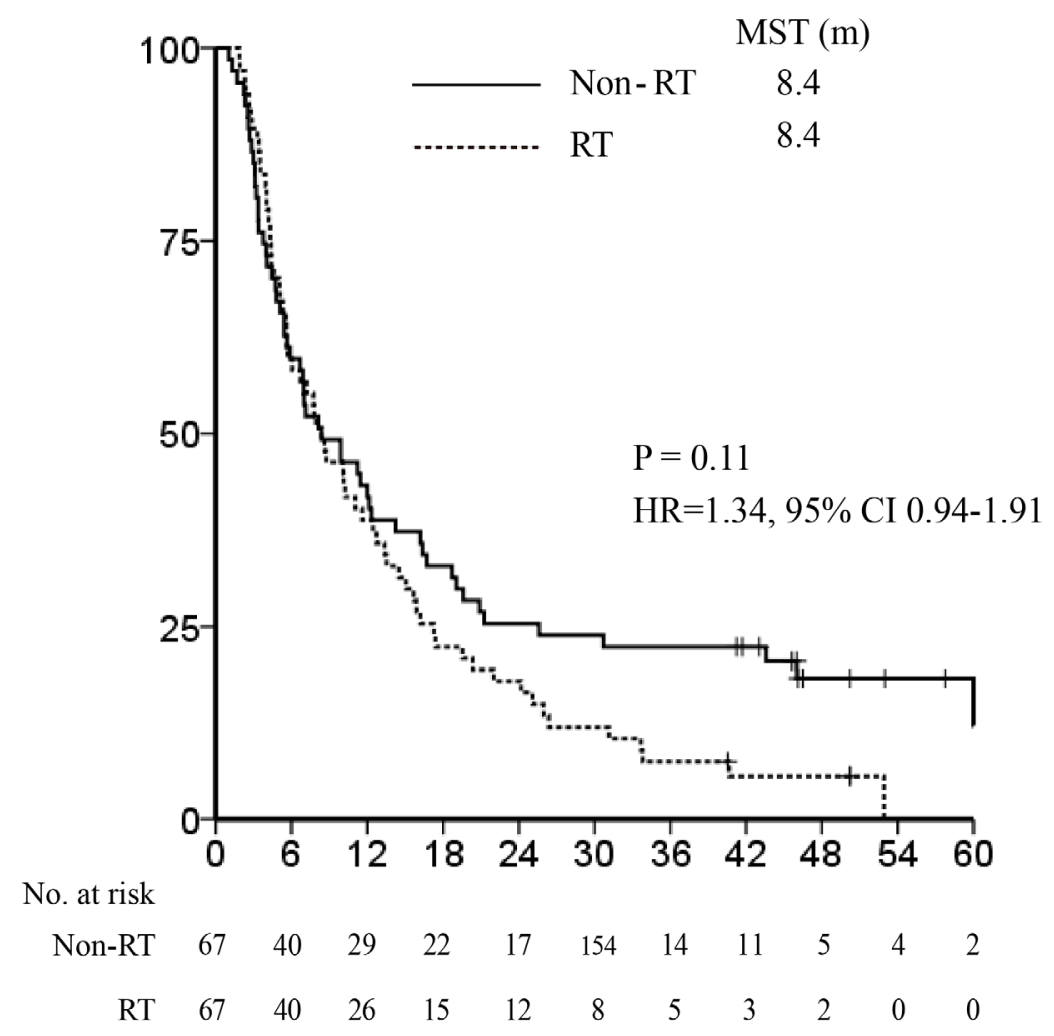

Figure 2: Median survival time after propensity score matching: radiotherapy vs. non-radiotherapy groups. The KaplanMeier survival curve in the entire cohort shows that the median survival time (MST) of the radiotherapy (RT) group (8.4 months) was not significantly different from that of non-RT group (8.4 months; hazard ratio $1.34,95 \%$ confidence interval $0.94-1.91, P=0.11)$.
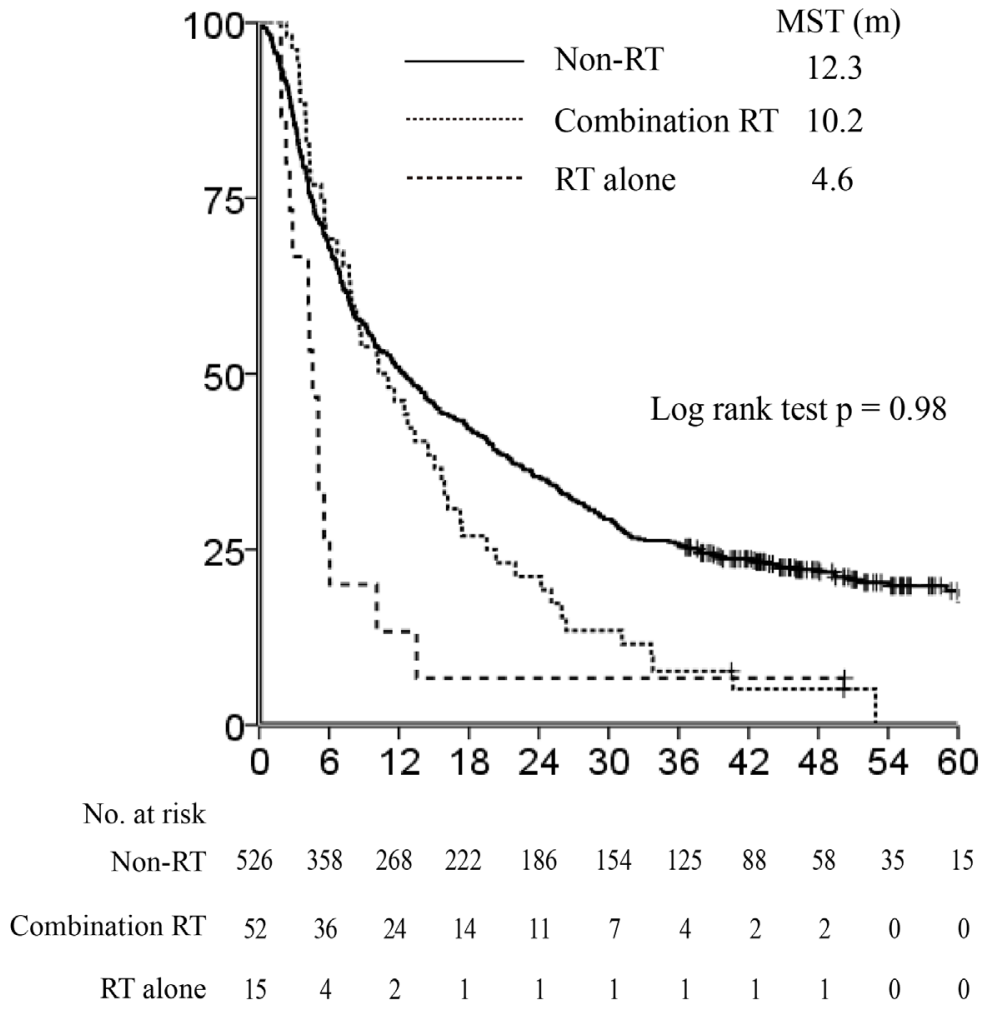

Figure 3: Difference of survival outcome between patients who underwent combination radiotherapy (RT) and RT alone. The non-RT and combination RT groups had significantly longer median survival times (MST) than the RT-alone group (12.3 vs. 10.2 vs. 4.6 months, respectively, $P=0.0002$ ). 


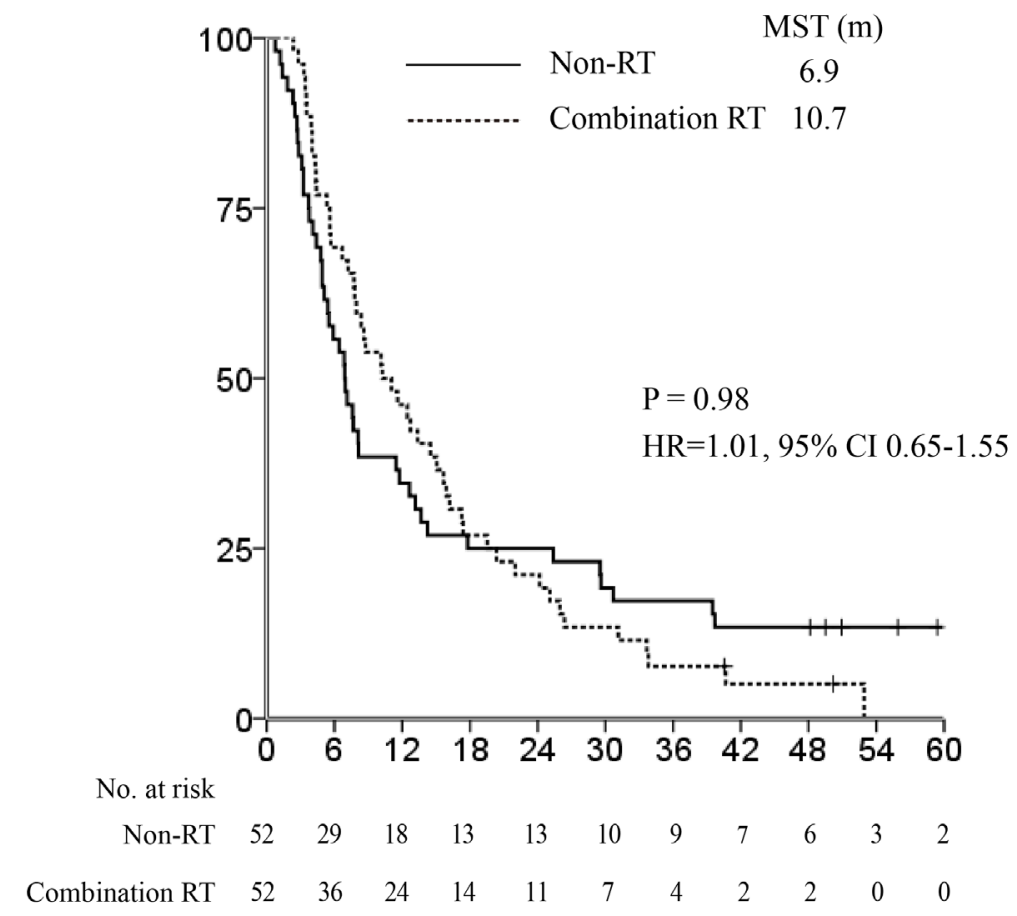

Figure 4: Median survival time after propensity score matching: combination radiotherapy vs. non-radiotherapy groups. The survival outcomes in the combination radiotherapy (RT) and non-RT groups were not statistically different, although the combination RT group had a longer median survival time (MST) (10.7 vs. 6.9 months respectively, hazard ratio 1.01, 95\% confidence interval 0.65-1.55, $P=0.98)$.

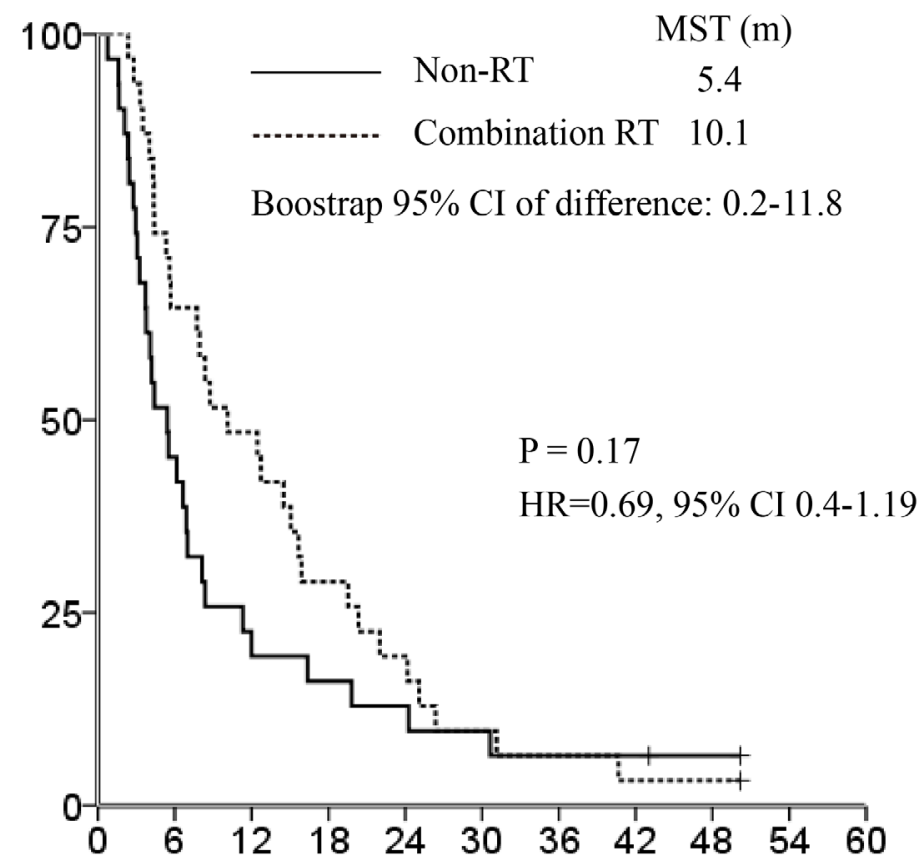

No. at risk

$\begin{array}{rlllllllllll}\text { Non-RT } & 31 & 14 & 7 & 5 & 4 & 3 & 2 & 2 & 1 & 0 & 0 \\ \text { Combination RT } & 31 & 20 & 15 & 9 & 6 & 3 & 2 & 1 & 1 & 0 & 0\end{array}$

Figure 5: Median survival time after propensity score matching: combination radiotherapy vs. non-radiotherapy groups in the subset of patients with tumor sizes $\geq 10 \mathrm{~cm}$. There was a significant difference in median survival time (MST) between the 2 groups (10.1 vs. 5.4 months, bootstrap 95\% confidence interval [CI] of difference in MST, 0.2-11.8). The combination RT group achieved better overall survival despite no statistical significance (hazard ratio $0.69,95 \%$ CI $0.4-1.19, P=0.17$ ). 


\section{OS in combination RT versus non-RT groups after $P S M$ analysis in patients with tumor sizes $\geq 10 \mathrm{~cm}$}

Subsequently, we performed PSM between the patients in the combination RT and non-RT groups with tumor sizes $\geq 10 \mathrm{~cm}(n=31$ and $n=169$, respectively) to identify the survival benefit of RT in liver-confined bulky non-resectable tumors. There was a significant difference in age and tumor size between the 2 groups before PSM (Table 3). PV invasion and HCC etiology were also significantly different between the groups $(P=0.072$ and $P=0.06$, respectively). Thus, we performed PSM via logistic regression using age, tumor size, $\mathrm{PV}$ invasion, and HCC etiology; all patient characteristics were balanced after PSM analysis. On survival analysis after PSM, we observed a significant difference in MST between the 2 groups (10.1 vs. 5.4 months respectively, bootstrap $95 \%$ CI of difference in MST, 0.2-11.8; Figure 5). The combination RT group achieved better OS, although the difference was not statistically significant (HR $0.69,95 \%$ CI 0.4-1.19, $P=0.17$; Figure 5).

\section{DISCUSSION}

This nationwide retrospective cohort study utilizing PSM analysis demonstrated that there was no significant difference in OS between the RT and non-RT groups for liver-confined but non-resectable BCLC stage C HCC patients. Furthermore, the OS was not significantly different when comparing the combination RT to the non-RT groups after PSM. However, the combination RT group exhibited longer MST, although without statistical significance. Additionally, we performed PSM between combination RT and non-RT subgroups for patients with tumor sizes $\geq 10 \mathrm{~cm}$. We found that the combination RT group exhibited significantly improved MST compared to the non-RT group in the subset of patients with larger tumors, and that the combination RT group achieved better OS (although the improvement was not statistically significant).

Our findings are subject to certain limitations; for example, this study was retrospective, and the number of patients included in the RT group was small. The patients were heterogeneous and the proper descriptions of RT modality, total doses and fractionations were lacking. Furthermore, there is no data regarding clinical events and toxicity available through our database. Despite these drawbacks, this study is the first to use a single nationwide multi-center cohort to investigate the survival benefit of RT in liver-confined but non-resectable BCLC stage C HCC patients. Additionally, there was a significant difference in MST between the combination RT and nonRT groups in the subset of patients with bulky tumors.

Large-size HCCs are known to have higher AFP levels, higher rates of microscopic and macroscopic vascular invasion, more advanced stages, and rupturing compared to small HCCs $[17,18]$. The prognosis of this disease is dismal, with a 5-year disease-free survival rate of $12.7-38.6 \%$ and a 5 -year OS rate of $16.7-40.2 \%$ despite radical resection [17-21]. However, resectable cases do not account for an appreciable portion of large HCC patients [10]. Several types of treatments have been performed for huge HCC, including trans-arterial therapy, chemotherapy, and RT [22-25]. Recent studies have demonstrated that combining RT with other treatments, such as trans-arterial therapy or hepatic arterial infusion chemotherapy (HAIC), is effective for large HCC [25-27]. Kim et al. reported that RT with concurrent HAIC (HAICCRT) followed by HAIC or RT plus TACE resulted in excellent intrahepatic control and improvement of survival (MST: 12.8 months for HAICCRT and 15.3 months for RT plus TACE) for nonresectable very large HCCs [25]. Zhong et al. investigated the safety and efficacy of stereotactic body radiotherapy combined with TACE for large HCC and reported excellent therapeutic outcomes, with an objective response rate of 79.1\% and MST of 12.2 months [26]. Similar to the results of previous studies, our findings indicate that RT combined with another treatment, particularly transarterial therapy, could enhance survival. These findings indicate the clinical benefit of choosing RT for large nonresectable $\mathrm{HCC}$ as the preferred treatment. In principle, a prospective randomized clinical trial is required to verify our findings regarding the survival benefit of additional RT for large non-resectable HCC.

Our findings demonstrated that the combination RT group achieved better OS in patients with tumor sizes $\geq 10 \mathrm{~cm}$, although the improvement was not significant. Generally, MST may be more appropriate for evaluating treatment outcomes of patients with poor prognoses. Indeed, significantly longer MST was demonstrated in the combination RT group than in the non-RT group in this study.

In conclusion, this nationwide retrospective cohort study demonstrates that the addition of RT to other treatments is associated significantly with improvement of MST for large HCCs by approximately 5 months. RT as a combined modality can be considered a therapeutic option for liver-confined but non-resectable BCLC stage $\mathrm{C}$ large HCC patients.

\section{METHODS AND MATERIALS}

\section{Multi-center hepatocellular carcinoma cohort}

HCC data from the Korea Central Cancer Registry were used to perform the systemic randomized sampling. This database was based on information collected from 
47 institutions in Korea; patients enrolled in this database underwent treatment for HCC between 2008 and 2010. This database included information on age; sex; PS; smoking history; pack years; tumor size; AFP levels; Child-Pugh class or score; number of tumor masses; nodal metastasis; PV, hepatic vein, bile duct, and hepatic artery invasion; HCC etiology; and survival. Staging was determined according to the BCLC staging system [1]. $\mathrm{HCC}$ was diagnosed according to the practice guidelines for diagnosis and treatment of HCC of the KLCSG [12, 13]. HCC was defined as pathologic confirmation of HCC or compatible radiological findings with the elevation of serum AFP level ( $>400 \mathrm{IU} / \mathrm{mL}$ before 2009 or $>200 \mathrm{IU} /$ $\mathrm{mL}$ after 2009) $[12,13]$. If AFP levels were lower than the cut-off values (i.e., $\leq 400 \mathrm{IU} / \mathrm{mL}$ before 2009 or $\leq 200$ $\mathrm{IU} / \mathrm{mL}$ after 2009), HCC was diagnosed by radiological findings using at least two imaging modalities $[12,13]$.

\section{Patient selection and groups}

There were 4596 patients in total; inclusion criteria were liver-confined, non-resectable BCLC stage C HCC. We excluded patients according to the following criteria: 1) BCLC stages A, B, and D; 2) distant metastasis; 3) patients who underwent surgery as the first treatment or had no treatment; or 4) missing clinical factor information. Ultimately, 593 patients were included in this study. Sixtyseven patients were treated with RT and defined as the RT group. The remaining patients were considered the non-RT group. In the RT group, $52(77.6 \%)$ patients underwent combination treatments involving other modalities within 4 weeks after the initial treatment; these patients were defined as the combination RT group.

\section{Treatments}

RT, sorafenib, systemic chemotherapy, trans-arterial therapy, and local ablation therapy were performed on patients in this study. Trans-arterial therapy included trans-arterial chemoembolization (TACE) with gelform, trans-arterial chemolipiodolization without gelform, transarterial therapy without gelform or lipiodol, TACE with beads, and radioembolization. The information regarding regimens for systemic chemotherapy was not available in the database; however, we expect that most patients in this study were treated with systemic chemotherapy regimens according to the KLCSG practice guidelines for diagnosis and treatment of $\mathrm{HCC}[12,13]$. Local ablation therapy consisted of radiofrequency ablation, ethanol ablation, and other ablation therapies. For the 52 combination RT patients, the other therapies included sorafenib, systemic chemotherapy, and trans-arterial therapy in 13, 2, and 37 patients, respectively. In the non-RT group, local ablation therapy was administered to 34 patients $(6.5 \%)$, trans-arterial therapy to 444 patients $(84.4 \%)$, systemic chemotherapy to 32 patients $(6.1 \%)$, and sorafenib to 16 patients $(3.0 \%)$.

\section{Study design}

The study was performed and reported in accordance with the recommendations of the Strengthening the Reporting of Observational Studies in Epidemiology statement [14]. This study was approved by the internal review boards at Severance hospital (IRB no. 4-20151157). First, we compared the baseline characteristics between the treatment groups to evaluate the differences in confounding covariates. Next, we performed PSM analysis to adjustment for variables that showed statistically significant differences, and then analyzed the survival difference between treatment groups.

\section{Statistical analysis}

The primary endpoint was OS, which was defined as the period between the treatment start date and the date of death or last follow-up. Before PSM analysis, OS for all patients included in this study was calculated using the Kaplan-Meier method and compared between the RT and non-RT groups using the log-rank test. To minimize potential confounding effects of covariates and selection bias, we utilized PSM analysis for data balancing between groups [15]. For assessment of the difference in potential confounders between the RT and non-RT groups, we performed Pearson's $\chi^{2}$ test or Fisher's exact test to compare differences in nominal variables in patient characteristics; differences in continuous variables were analyzed using the Mann-Whitney U test.

We performed 1 to 1 ratio PSM analysis thrice to compare 1) the RT group to the non-RT group, 2) the combination RT group to the non-RT group, and 3 ) the combination RT group to the non-RT group in the subset of patients with tumor sizes $\geq 10 \mathrm{~cm}$. After performing each PSM analysis, we compared the baseline characteristics between the 2 groups by using conditional logistic regression. For survival analysis after PSM, we performed Cox regression model analyses to compare the risks of outcome in each group using robust standard errors that considered the clustering of matched pairs. We graphed survival curves using Kaplan-Meier estimates, and compared the OS of treatment groups using the methods devised by Klein and Moeschberger [16].

All statistical analyses were 2 -sided. P values $\leq 0.05$ were considered statistically significant. All statistical analyses were conducted using the SAS software, version 9.2. 


\section{Ethics statement}

This study was approved by the Institutional Review Board at Severance Hospital. All clinical investigations have been conducted according to the principles expressed in the Declaration of Helsinki.

\section{ACKNOWLEDGMENTS AND FUNDING}

This study was supported by a grant of the Korean Health Technology R\&D Project (A121982), Ministry of Health \& Welfare, Republic of Korea.

\section{CONFLICTS OF INTEREST}

The authors who have taken part in this study declared that they do not have anything to disclose regarding funding or conflict of interest with respect to this manuscript.

\section{REFERENCES}

1. de Lope CR, Tremosini S, Forner A, Reig M, Bruix J. Management of HCC. J Hepatol. 2012; 56 Suppl 1:S75-87.

2. Llovet JM, Ricci S, Mazzaferro V, Hilgard P, Gane E, Blanc JF, de Oliveira AC, Santoro A, Raoul JL, Forner A, Schwartz M, Porta C, Zeuzem S, Bolondi L, Greten TF, Galle PR, Seitz JF, Borbath I, Haussinger D, Giannaris T, Shan M, Moscovici M, Voliotis D, Bruix J, Group SIS. Sorafenib in advanced hepatocellular carcinoma. N Engl J Med. 2008; 359:378-390.

3. Cheng AL, Kang YK, Chen Z, Tsao CJ, Qin S, Kim JS, Luo R, Feng J, Ye S, Yang TS, Xu J, Sun Y, Liang H, Liu J, Wang J, Tak WY, Pan H, Burock K, Zou J, Voliotis D, Guan Z. Efficacy and safety of sorafenib in patients in the Asia-Pacific region with advanced hepatocellular carcinoma: a phase III randomised, double-blind, placebocontrolled trial. Lancet Oncol. 2009; 10:25-34.

4. Hadziahmetovic M, Shirai K, Chakravarti A. Recent advancements in multimodality treatment of gliomas. Future Oncol. 2011; 7:1169-1183.

5. Cervantes A, Chirivella I, Rodriguez-Braun E, Campos S, Navarro S, Garcia Granero E. A multimodality approach to localized rectal cancer. Ann Oncol. 2006; 17 Suppl 10:x129-134.

6. Zaorsky NG, Trabulsi EJ, Lin J, Den RB. Multimodality therapy for patients with high-risk prostate cancer: current status and future directions. Semin Oncol. 2013; 40:308321.

7. Yoon SM, Lim YS, Won HJ, Kim JH, Kim KM, Lee HC, Chung YH, Lee YS, Lee SG, Park JH, Suh DJ. Radiotherapy plus transarterial chemoembolization for hepatocellular carcinoma invading the portal vein: longterm patient outcomes. Int J Radiat Oncol Biol Phys. 2012;
82:2004-2011.

8. Lee HS, Choi GH, Choi JS, Kim KS, Han KH, Seong J, Ahn SH, Kim do Y, Park JY, Kim SU, Kim BK. Surgical resection after down-staging of locally advanced hepatocellular carcinoma by localized concurrent chemoradiotherapy. Ann Surg Oncol. 2014; 21:3646-3653.

9. Yoon HI, Song KJ, Lee IJ, Kim DY, Han KH, Seong J. Clinical Benefit of Hepatic Arterial Infusion Concurrent Chemoradiotherapy in Locally Advanced Hepatocellular Carcinoma: A Propensity Score Matching Analysis. Cancer Res Treat. 2015. doi:10.4143/crt.2014.276.

10. Hawkins MA, Dawson LA. Radiation therapy for hepatocellular carcinoma: from palliation to cure. Cancer. 2006; 106:1653-1663.

11. Kim TH, Kim DY, Park JW, Kim SH, Choi JI, Kim HB, Lee WJ, Park SJ, Hong EK, Kim CM. Dose-volumetric parameters predicting radiation-induced hepatic toxicity in unresectable hepatocellular carcinoma patients treated with three-dimensional conformal radiotherapy. Int J Radiat Oncol Biol Phys. 2007; 67:225-231.

12. Park JW, Korean Liver Cancer Study G, National Cancer C. [Practice guideline for diagnosis and treatment of hepatocellular carcinoma]. Korean J Hepatol. 2004; 10:8898.

13. Korean Liver Cancer Study G, National Cancer Center K. [Practice guidelines for management of hepatocellular carcinoma 2009]. Korean J Hepatol. 2009; 15:391-423.

14. von Elm E, Altman DG, Egger M, Pocock SJ, Gotzsche PC, Vandenbroucke JP, Initiative S. The Strengthening the Reporting of Observational Studies in Epidemiology (STROBE) statement: guidelines for reporting observational studies. Lancet. 2007; 370:1453-1457.

15. D'Agostino RB, Jr. Propensity score methods for bias reduction in the comparison of a treatment to a nonrandomized control group. Stat Med. 1998; 17:2265-2281.

16. Klein JP MM. Survival analysis: techniques for censored and truncated data.: Springer; 2003.

17. Choi GH, Han DH, Kim DH, Choi SB, Kang CM, Kim KS, Choi JS, Park YN, Park JY, Kim do Y, Han KH, Chon $\mathrm{CY}$, Lee WJ. Outcome after curative resection for a huge ( $>$ or $=10 \mathrm{~cm}$ ) hepatocellular carcinoma and prognostic significance of gross tumor classification. Am J Surg. 2009; 198:693-701.

18. Yeh $\mathrm{CN}$, Lee WC, Chen MF. Hepatic resection and prognosis for patients with hepatocellular carcinoma larger than $10 \mathrm{~cm}$ : two decades of experience at Chang Gung memorial hospital. Ann Surg Oncol. 2003; 10:1070-1076.

19. Shrager B, Jibara GA, Tabrizian P, Schwartz ME, Labow DM, Hiotis S. Resection of large hepatocellular carcinoma $(>/=10 \mathrm{~cm})$ : a unique western perspective. J Surg Oncol. 2013; 107:111-117.

20. Yang XD, Pan LH, Wang L, Ke Y, Cao J, Yang C, Zhong JH, Luo W, Guo J, Li LQ. Systematic Review of Single Large and/or Multinodular Hepatocellular Carcinoma: 
Surgical Resection Improves Survival. Asian Pac J Cancer Prev. 2015; 16:5541-5547.

21. Hwang S, Lee YJ, Kim KH, Ahn CS, Moon DB, Ha TY, Song GW, Jung DH, Lee SG. Long-Term Outcome After Resection of Huge Hepatocellular Carcinoma $>/=10 \mathrm{~cm}$ : Single-Institution Experience with 471 Patients. World J Surg. 2015; 39:2519-2528.

22. Li JH, Xie XY, Zhang L, Le F, Ge NL, Li LX, Gan YH, Chen Y, Zhang JB, Xue TC, Chen RX, Xia JL, Zhang BH, Ye SL, Wang YH, Ren ZG. Oxaliplatin and 5-fluorouracil hepatic infusion with lipiodolized chemoembolization in large hepatocellular carcinoma. World J Gastroenterol. 2015; 21:3970-3977.

23. Lee YB, Lee DH, Cho Y, Yu SJ, Lee JH, Yoon JH, Lee HS, Kim HC, Yi NJ, Lee KW, Suh KS, Chung JW, Kim YJ. Comparison of transarterial chemoembolization and hepatic resection for large solitary hepatocellular carcinoma: a propensity score analysis. J Vasc Interv Radiol. 2015; 26:651-659.
24. Zhu SL, Zhong JH, Ke Y, Ma L, You XM, Li LQ. Efficacy of hepatic resection $v s$ transarterial chemoembolization for solitary huge hepatocellular carcinoma. World J Gastroenterol. 2015; 21:9630-9637.

25. Kim KH, Kim MS, Chang JS, Han KH, Kim do Y, Seong J. Therapeutic benefit of radiotherapy in huge $(>/=10$ $\mathrm{cm})$ unresectable hepatocellular carcinoma. Liver Int. 2014; 34:784-794.

26. Zhong NB, Lv GM, Chen ZH. Stereotactic body radiotherapy combined with transarterial chemoembolization for huge $(>/=10 \mathrm{~cm}$ ) hepatocellular carcinomas: A clinical study. Mol Clin Oncol. 2014; 2:839844.

27. Shin YJ, Kim MS, Yoo SY, Cho CK, Seo YS, Kang JK, Park SC, Han CJ, Kim SB, Lee BH, Lees DH. Pilot study of stereotactic body radiotherapy for huge hepatocellular carcinoma unsuitable for other therapies. Tumori. 2010; 96:65-70. 